\title{
Crossing Boundaries: An Introductory Essay
}

\author{
JUDITH BECKER \\ University of Michigan
}

THE very first issue of EMR (2006) began with a vigorous examination of the kinds and uses of experimental method and empirical research on music, and a commitment to the crossing of the boundaries between the scholarly approaches of historical musicology and music theory on one hand, and the psychology of music on the other (Clarke, 2006; Cook, 2006; Honing, 2006; Huovinen, 2006). Related to that first issue but with a difference, this special issue is devoted to an examination of one failure in crossing boundaries between music psychology and ethnomusicology with the hope that this instance may illuminate some issues that separate these disciplines even when the participating parties desire closer cooperation.

Ethnomusicology, with its emphasis on intensive fieldwork, the integration of musical and cultural analysis, and a concomitant distrust of either broad comparative studies or overarching theories of musical experience, is not featured very prominently in that first EMR issue. As Nicolas Cook explained:

"And if musical practices ... only acquired meaning through their relationship to that culture,

then making comparisons between cultures was both intellectually and ideologically

illegitimate." (Cook, 2006, p. 8)

Ethnomusicologists are committed to the idea that the musical, analytical and evaluative tools developed within one musical system cannot be superimposed upon another musical system. Unrelated musical systems are non-commensurable (Becker, 1986). Our forte is in our in-depth descriptions of the specialness of particular genres in particular societies, not in broad comparative studies. In his essay, "Art as a Cultural System" (1983), the anthropologist Clifford Geertz describes the culture-specific sensibilities that inform an indepth understanding of Yoruban cicatrix, Abelam painting, quattrocentro Italian painting, and Islamic poetry. In a pithy summation of the thrust of the whole article, he claims "Art and the equipment to grasp it are made in the same shop" (p. 118).

How different are the aims of music psychology:

“As I have argued elsewhere (Clarke, 2003) in very broad terms, psychology tends to be concerned with general principles (of perception, memory, action, thought), frequently stripped of their specific cultural and historical context, and often proposed as cross-cultural or even universal human attributes." (Clarke, 2006, p. 29).

If empirical musicology is concerned with inductively drawing certain broadly applicable abstractions about musical perception, musical understandings, or musical emotion, then ethnomusicology would seem to be an impossible partner. As a recent convert to empirical methods, I feel I can confidently represent the majority of ethnomusicologists in pointing out some methodologies of music psychology that present particular barriers for communication between ethnomusicologists and psychologists, or ethnomusicologists and empiricists in general.

1. Psychological studies overwhelmingly deal with Western art music. Also, experimental subjects are often university students. For many ethnomusicologists who have spent years studying another musical system within its cultural context, Western classical music is no longer the unmarked form, nor young people the ideal informants. This limited perspective of many music psychology articles leads to suspicion concerning the generalizations about musical perception, musical understandings or musical emotions that are sometimes proposed.

2. Psychological experiments with music are often concerned with very small matters. A scientist tries to limit or control multiple variables in order to be able to attain verifiable results. The ethnomusicologist is more interested in musical meaning writ large. "Meaning" always refers to that which matters to the musicians and listeners of a particular genre of music, not that which matters to the analyst.

3. Psychological experiments rely heavily upon statistical analyses and statistical verification reaching the 5\% "significance" measure (Huron, 1999, p. 34; Clarke, 2006, p. 29). For the ethnomusicologist, any small matter may be felt to be "significant." Ethnomusicologists distrust statistics when it comes to matters so intimate and so analogical as musical expression and reception. We almost invariably follow qualitative methods and resist the lumping of humans into abstract groupings that distorts or erases their individuality.

"For many humanistically-inclined scholars, however, there remains something inherently wrong about quantifying human experiences - especially those experiences related to human attachment, esthetic experience, and spiritual life." (Huron, 1999, p. 24).

Also, most ethnomusicologists can't read the statistics, find the numbers appearing in Anova tests, or what Huron calls "strings of funny Greek letters and numbers that often pepper the prose" (Huron 1999, p. 16), unaesthetic, unreadable, and a disruption of the flow of the article.

Thus, the objections of the ethnomusicologist to empirical approaches are both methodological and epistemological in which aesthetics and morality are intimately imbricated. I believe that it is the largely 
unexamined involvement of aesthetics and morality in scholarly approaches that makes these divides fraught with emotion, and makes them seem so intractable. To the scientist, the humanist may seem fuzzy-headed, lacking rigor, gullible, and accepting of theories with poor evidence. To the humanist, the scientist may seem to be wearing blinders, unaware of the subtleties and complexities of our relationships to musical experience.

Nonetheless, there are members of the Society for Ethnomusicology who are totally familiar with and comfortable using empiricist methods, and who publish in science-oriented journals. Increasingly, there are mainstream ethnomusicologists interested in crossing the boundary between empirical/ scientific methodology and the humanistically grounded field of ethnomusicology. Many of us believe that our intimate knowledge of non-Western musical systems can help psychologists escape from the often unspoken assumption that what is the case for Western music holds true for all musics. We may recognize "the need for higher standards of evidence in support of knowledge claims" (Huron, 1999, p. 29), or may feel that empirical methodology can help support our observations and our theoretical speculations (Clarke, 2006, p. 10). Some of us have come to terms with the reductionist tendencies of empirical research, taking comfort in Huron's observation that "A helpful distinction is to treat "reductionism" as a potentially useful strategy for discovery rather than a belief about how the world is (Huron, 1999, p. 22).

And yet, obstacles remain. Ethnomusicologists and music psychologists mostly publish in different journals and reach different audiences with not much overlap. The recent pre-conference symposium entitled "New Directions in Cognitive Ethnomusicology" (Oct. 24, 2007, Ohio State University) inadvertently highlighted the fact that some members of the Society for Ethnomusicology think that "cognitive ethnomusicology" is an oxymoron. Empirical methods were both staunchly supported and vigorously attacked. Still, the very fact that such a symposium took place at an annual meeting of the Society for Ethnomusicology bears witness to an increased interest in scholarly approaches largely derived from science-based perspectives.

The issue for me is a personal one, and I suspect that the negative outcome of one of my attempts to cross boundaries can illuminate and illustrate some of the barriers that continue to interfere with an open dialogue between differing approaches to knowledge. In an era in which "interdisciplinarity" has become a kind of mantra, verbally subscribed to by nearly everyone, disciplines continue to police their own boundaries.

\section{Embracing empiricism}

After a long career as an ethnomusicologist whose writings focused on Southeast Asian musical traditions, I became fascinated by the phenomenon of trancing, a relatively commonplace event in Southeast Asian religious practices. Every trancing community has a theory of what is happening during trance, and why. Trancing is often theorized as a method of communication with unseen beings, demons or deities. Or, trancing is believed to facilitate communion with Allah, or instantiate the presence of the Holy Spirit. Trancing is a psychological event and a physiological event. But no religious community, as far as I know, presents a physiological counterpart to their religious explanation of trance; the physiology of trancing remains a mystery. In spite of striking similarities in the behavior of trancers far distant geographically (Rouget, 1985, p. 11; Becker, 2004 , pp. 38-44), we understand little of what is happening within the bodies of trancers. Trancing seemed to me to be a phenomenon that cried out for an empirical approach.

In my book, Deep Listeners: Music, Emotion, and Trancing (2004), I proposed the hypothesis that strong emotional response to the accompanying music was one of the catalysts for entering trance. I also proposed that secular "deep listeners," those folks who are deeply moved by listening to music they love, have physiological/ emotional reactions similar to those of trancers. The only valid way to begin to verify these hypotheses was to pursue an empirical research project. Except for a long-standing interest in science, nothing in my education prepared me to do this. Nonetheless, with the help of friends and consultants in scientific disciplines, I decided to try. The only empirical, physiological measure I could handle or afford was to measure the GSR (galvanic skin response) of the participants in the experiment while listening to their favorite music.

Although the initial impulse to study trancing began in Southeast Asia, for the empirical research project I focused on more local religious ecstatics, i.e. Pentecostals from Ypsilanti, Michigan.

The first obstacle to my embrace of empiricism was the failure to secure funding for the experiments. Initially, I tried looking for outside funding. I was told that the project was too scientific for NEH or NEA, and not scientific enough for NIH. Every foundation I approached refused me before I got so far as actually preparing an application.

I then tried securing inside funding. For two years in a row I was refused funding from my own university. The lack of experience in GSR testing was the primary reason given for refusing funding as demonstrated by the excerpted quote below.

"Use of physiological measures but no evidence of any experience or expertise with physiological measures and their interpretation."

In spite of the refusals of the university research panel to fund this research, there were, in both year's reviews, reviewers who were genuinely enthusiastic and who recommended support. My suspicion is that those 
who were opposed were vehemently opposed because of the nature of the proposed research involving music, emotion, and especially, implicating trance.

Compounding these frustrations, all attempts to enlist the interest and collaboration of members of the University of Michigan Department of Psychology failed. In at least one instance, the reason was specifically given as the issue of trance.

Undeterred, Joshua Penman my research assistant, a composer with a background in neuroscience, and I ran the experiments and did the analyses (with professional help), and jointly wrote an article about our results. We wanted to publish in a scientific journal. Our first choice was the journal Psychology of Music. The article was tentatively accepted, but over the course of more than a year the article was three times sent out to reviewers and three times sent back to us. Each time, extensive rewriting was requested. (As when applying for funding, there were also enthusiastic reviewers who did not request extensive revisions.) Aside from very many useful comments (I remain awed by the thoroughness of the review process of Psychology of Music), there were three categories of critique that we were unable to address.

The first category of unaddressable critique related to differences of understandings about the relation between music and emotion between psychologists (in general) and ethnomusicologists. For example, many of our reviewers believed that one's emotional reactions to the music are exclusively due to pin-pointable structural aspects of the music, rather than the generalized impact of the music, and/or any number of extra-musical factors. The belief that very specific structural aspects of the music are the sole source of musical emotional arousal contributed to numerous reviewer comments such as:

"It borders on the amazing that in each of the groups the participants' responses to the two control pieces [as opposed to self-selected pieces] were so similar that one could safely average across them. This implies, as do several other aspects of the results, that the subjects were not responding differentially to the structural aspects of other people's choices at all, which goes against most of the "expressiveness" literature. In this study, associations (and their absence) seem to account for everything."

Within the disciplines of music psychology (Sloboda and Juslin, 2001, p. 95) and neuroscience (Levitin, 2006, pp. 217-240), and most recently by Juslin and Västfjall (2008), the problems with assuming an exclusively music-intrinsic reason for listener arousal has been addressed. But the Juslin and Västfjall article, quoted in the articles below, was not available to us at the time.

The second category of unaddressable critique was the challenging of our assumption that galvanic skin response, or ANS arousal, can be considered as a component of "emotional" response. This is a controversial issue within the field of psychology that, as outsiders, we were in no position to argue. But it was precisely the highly salient, outward emotionality of trancers (indicating ANS arousal) that first led me to my hypothesis concerning the relationship between emotional reactions to music and the onset of trancing. Since any bodily movement affects GSR, and trancers are always moving, the only way to know if the trancers were inclined to ANS arousal while listening to music was to separate them from the mobile trance situation. The argument within the field of psychology concerning whether or not ANS arousal can be called emotion was not one we could take on. One sympathetic reviewer, writing in response to an unsympathetic reviewer, wrote:

"I think this point is fairly easy to recover from. I agree that physiological response is not necessarily equal to emotion, but treating it as a possible component of emotion has a long Nor did we. tradition, and I don't see why this paper should take the brunt of it."

The third category of unaddressable critique, I believe, was for many reviewers the elephant in the room, i.e., we were writing about religious ecstatics. If there is a taboo subject among psychologists and scientists in general, it is altered states. Some reviewers were open about this problem; for others, I suspect, it was an unnerving component of the study. One reviewer wrote:

“... the problems of getting a genuine and solid experimental handle on the study of religious trance seem formidable."

The final reviewer for Psychology of Music requested nearly as many revisions as the first set of three reviewers. He/she began with:

"This revised manuscript is an improvement, and the concept of the research is fascinating and should be of considerable interest to readers of Psychology of Music. However there are some significant problems with the paper..."

At this point, I decided to withdraw the article. By this time Josh, my research assistant, had graduated, and I had lost my enthusiasm for pursuing what now felt like an impossible achievement - publishing an article in a scientific journal. I wanted to rewrite it for an audience I understood, who were comfortable with the idea of ecstatic states, and whose criteria for excellence in scholarship were those with which I was familiar.

Along the way, I realized that I had learned a lot about the difficulties of trying to cross this particular boundary, and also about the different expectations of the disciplines concerning what counts as evidence, what counts as a reasonable argument, how one presents an argument, and the differing underlying assumptions about 
musical experience. I do not believe that there are "good guys" or "bad guys" in this narrative. Everyone was acting in accord with his or her own vision of what is good scholarship.

Was our failure due to our own shortcomings in not becoming thoroughly versed in the protocols and expectations of another discipline? Or, was the failure due to too stringent protocols and expectations for publication in a psychological journal?

I am inclined to accept both reasons. I have come to terms with certain disciplinary barriers that cannot and perhaps should not be breached. Ethnomusicology should not give up its insistence upon the recognition of culturally-inflected hearings of music. Music psychology should not give up its insistence upon controlled experiments and statistically-derived conclusions. Ethnomusicology should not give up its commitment to the importance of the phenomenology of the single musician or of the single listener. Music psychology should not give up its reliance upon inductively drawing conclusions that may indicate some general or "limited" universal application. Nor should ethnomusicology give up its exploration of large issues that are resistant to empirical verification. There are some good reasons for policing disciplinary boundaries, as well as some good reasons for not doing so.

Below is a manuscript combining the "humanities" and "sciences" versions, abbreviated for the sake of space. The "sciences" version was tailored for submission to Psychology of Music; the "humanities" version was rewritten for an audience of ethnomusicologists. But before submitting the "humanities" version for publication, I decided that a more interesting approach might be to juxtapose the two versions to stimulate a further dialogue. I am grateful to the journal editor of Empirical Musicology Review for allowing me to open up again the issues of cross-disciplinary research.

\section{REFERENCES}

Becker, J., (1986). Is Western Art Music Superior? The Musical Quarterly, 72(3): 341-359.

Becker, J., (2004). Deep Listeners: Music, Emotion, and Trancing. Bloomington, IN: Indiana University Press.

Clarke, E. F., (2003). Music and Psychology. In M. Clayton, T. Herbert \& R. Middleton (Eds.), The Cultural Study of Music. A Critical Introduction. New York: Routledge, pp. 113-123.

Clarke, E. F., (2006). Commentary on Huovinen's "Varieties of Musicological Empiricism." Empirical Musicology Review, 1(1): 28-32.

Cook, N., (2006). Border Crossings: A Commentary on Henkjan Honing's "On the Growing Role of Observation, Formalization and Experimental Method in Musicology. Empirical Musicology Review, 1(1): 7-11.

Geertz, C., (1983). Art as a Cultural System. In Local Knowledge: Further Essays in Interpretive Anthropology. New York: Basic Books, Inc., pp. 94-120.

Honing, H., (2006). On the Growing Role of Observation, Formalization and Experimental Method in Musicology. Empirical Musicology Review, 1(1): 2-6.

Huovinen, E., (2006). Varieties of musicological empiricism. Empirical Musicology Review, 1(1): 12-27.

Huron, D., (1999). The New Empiricism: Systematic Musicology in a Postmodern Age. Berkeley, University of California [http://www.music-cog.ohio-state.edu/Music220/Block.lectures/].

Juslin, P. \& Västfjall, D., (2008) Emotional responses to music: The need to consider underlying mechanisms. Behavioral And Brain Sciences, 31, 5559-5575.

Levitin, D. J., (2006). This Is Your Brain on Music: The science of a human obsession. New York: Dutton.

Rouget, Gilbert, (1985). Music and Trance: A Theory of the Relations between Music and Possession. Translated from the French by Brunhilde Biebuyck. Chicago: University of Chicago Press.

Sloboda, J.A. \& Juslin, P.N. (2001). Psychological perspectives on music and emotion. In J. A. Sloboda \& P. N. Juslin (Eds.), Music and Emotion: Theory and Research. Oxford: Oxford University Press, pp. 71-104. 